\title{
Levels of Mind: against austerity in the Philosophy of Mind ${ }^{1}$
}

\author{
Níveis da mente: contra a austeridade na Filosofia da Mente
}

$\frac{\text { Pascal Engel }}{\text { Université de Genève }}$

Resumo: A filosofia da mente contemporânea, como grande parte da ciência cognitiva, favorece concepções austeras da mente, que buscam explicar a natureza do fenômeno mental a partir de um pequeno conjunto de princípios básicos. Psicologia associacionista, behaviorismo, teorias computacionais e teorias conexionistas da mente são visões deste tipo. Contra elas, argumento que não só a complexidade do fenômeno mental é tal que nenhuma teoria geral deste tipo pode ser possível, mas também que para cada tipo de fenômeno mental um tipo específico de teoria pode ser necessário. Advogo uma concepção da mente como formada por camadas, composta por um número de níveis distintos (mas basicamente teorias processuais dualistas da mente), cada uma tendo seus princípios específicos e tipo de complexidade. Esse modelo é ilustrado na noção de crença, que compreende vários níveis de complexidade e uma hierarquia estrutural. Concepções duais da cognição superior servem como base para este modelo multi-nível.

Palavras-Chave: Mente, Filosofia da Mente, crença, aceitação, teorias processuais dualistas da mente

Summary: Contemporary philosophy of mind, like much of cognitive science, favours austere conceptions of the mind, which hope to account for the nature of mental phenomena from a small set of basic principles. Associationist psychology, behaviourism, computational theories and connectionist theories of mind are views of this kind. Against these, I argue that not only the complexity of mental phenomena is such that no general theory of this sort may be possible, but also that for each kind of mental phenomenon a specific kind of theory may be necessary. I advocate a layered conception of the mind, composed of a number of distinct levels (but basically dual process theories), each having its specific principles and kind of complexity. This model is illustrated on the notion of belief, which comprises various levels of complexity and a hierarchical structure. Dual aspect conceptions of higher cognition serve as a basis for this multi-level model.

Key-Words: Mind, Philosophy of Mind, belief, acceptance, dual process theories of mind.

\section{Introduction: austerity and richness}

Psychology in the XXth century has been dominated by what we may call austere conceptions of the mind. An austere conception of the mind is one which hopes to account for the mind and its operations with only a limited number of entities and laws. The paradigm of an austere conception of mind is Hume's atomism and associationism, which he famously advertises in the Introduction of

\footnotetext{
${ }^{1}$ Invited lecture, Institut International de Philosophie, XXI ${ }^{\text {th }}$ World Congress of Philosophy, Istanbul August 2003. Texto inédito com versão parcial em francês: "Croyance, métacroyance, surcroyance" in Joëlle Proust \& E. Pacherie (eds). Philosophie et cognitio. Paris, Ophrys et Éditions de la MSH, 2004.
} 
the Treatise as a form of Newtonianism applied to (what was then called) "moral subjects".2 The successor of associationism, behaviourism, is also an austere conception, which hopes to reduce all mental phenomena to behaviour and to subsume all behaviours under the "law of effect" and the principles of operant conditioning. Austere conceptions were also facilitated by the advent of methods of measurement and statistics: even though there were different methods, it was hoped than one system only would work. ${ }^{3}$

Now it has often been said that, contrary to these austere conceptions, contemporary cognitive science has reintroduced richness within psychology, by renewing in part the old conceptions of faculty psychology, representing the mind as a complex collection of modules. Contemporary cognitive psychology generally distinguishes two axes of complexity: horizontal, when one considers the various functional relations between the competing modules, and vertical when one considers the levels of explanation from which a cognitive task can be examined. 4 In David Marr's famous terminology, any cognitive explanation of a given phenomenon has to move from a top "computational" or "functional" level, which describes the task to be executed, down to an intermediary algorithmic level which analyses the algorithm which performs the task, and the third, physical or bottom level, which analyses how the algorithm is implemented in the neurophysiology of an organism. It is not evident, however, contrary to what its advocates advertise, that cognitive psychology is not regulated by an ideal of austerity. For the distinction of levels is by no means an ontological one. It is epistemological. It does not carve out mental kinds, and it is perfectly compatible with a physicalistic picture according to which there are only physical entities.

And indeed the various kinds of representations which are posited by classical cognitive psychology are supposed to reduce to only one kind of

\footnotetext{
${ }^{2}$ Treatise of Human Nature, p. xvii (Selby-Biggs): "For me it seems evident, that the essence of the mind being equally unknown to us with that of the external bodies, it must be equally impossible to form any notion of its powers and qualities otherwise than from careful and exact experiments, and the observation of those particular effects which result from different circumstances and situations. And tho' we must endeavour to render all our principles as universal as possible, by tracing up our experiments to the utmost, and explaining all effects from the simplest and fewer causes." From now on quoted as THN.

${ }^{3}$ See the collection of essays in Krüger, Girenzer et alii (1987).

${ }^{4}$ Fodor 1983: a different taxonomy of vertical and horizontal.
} 
representations, symbolic representations endowed with a propositional or linguistic structure.5 In turn, these structures are supposed to be physical and hence implemented at the physical level, like the symbols processed in a computer (Pylyshyn, 1984; Fodor, 1987). Now it is often said that this "classical model" of cognitive architecture has been overcome by its connectionist rival, where computation is not achieved in terms of symbolic structures, but in terms of causal associations between parallel and distributive elements. But for all its riches, the connectionist architecture of mind is a very austere one, which in fact resembles much the associationist psychology of the $X X^{\text {th }}$ century.

Philosophy too has had his share of austerity, largely under the influence of these psychological theories, but also for its own reasons. Quine imposed on us the diet of extensional discourse, suspicious of such creatures of darkness as propositions, contents of propositional attitudes, meanings, and mental things. He proposed to account for meaning only with frugal notions such as assent, dissent, stimulus meanings, and sensory simulations. Relaxing but a little the quarantine on propositional attitudes decreed by Quine, Davidson proposed to construct a whole theory of interpretation of meaning and thought from a narrow empirical basis of sentences held true by speakers, extensional Tarskian theory of truth, causal facts in the environment and a few very general principles of rationality. Quine approved: "As long as intensional science can proceed autonomously and self contained, with no gaps of causality that intensional intrusions could serve to close, the sound strategy is the linguistic dualism of anomalous monism". (Quine, 1990, 72)

Austerity has its virtues: simpler theories are easier to test and have more explanatory power. The classical example is psychoanalysis, which is conceptually so wealthy that it is difficult to bring to experimental validation. The same could be said of traditional faculty psychology, of Gall's phrenology, and of common sense or folk psychology itself. Its categories are so numerous, it vocabulary is so rich, that it seems hopeless. Eliminativists and instrumentalists are prepared to keep it, but only for heuristic purposes. As Quine again says, approving the Churchlands and Dennett: "Intensional accounts can contribute to austere science by providing

${ }^{5}$ Witness, for instance, the debates about mental imagery. 
case studies for scientific analysis and perhaps even suggesting scientific hypotheses." Otherwise it is clear that it is not serious science.

Another source of austerity in contemporary philosophy of mind consists in the influence of Wittgensteinian views (whether or not they are actually Wittgenstein's). Eliminativists believe that mental concepts are contradictory and that they do not have a place within future science. Wittgensteinians believe that mental concepts are irreducibly vague, and do not lend themselves to precise definitions. They are a motley and do not form kinds. They only have family resemblances.

Now against these austere views, what would it mean to adopt a rich conception of mind? There are many ways in which this could be done. One could revert to Cartesian dualism, to faculty psychology, or to an Aristotelian conception of the soul. There are various ways of being rich, not all of which are desirable. Nobody envies Cresus. For instance no one, I suppose, would like to have a mentalistic ontology which would be as rich as that of astrology. I do not want to suggest that it is always better to be rich than poor. Frugality has its virtues. But my problem here is not so much about the ontology of mind, the number of mental things that there are. I do not believe that they should be multiplied without serious reasons for doing so. My problem is more with the explanatory power of psychological theories and of philosophical conceptions of mind, with what Quine calls their ideology.

The kind of austerity in the philosophy of mind which I want to oppose consists in reducing the number of mental states to a minimum, without trying to taxonomise these in their sub varieties. Even when it grants mentalistic notions, as it is the case for instance in contemporary functionalism, it consists in operating with only a modicum of mental notions in order to gain more generality and more testability. Here again Hume is the father of such approaches, when he declares about belief.

Now let any philosopher make a trial, and endeavour to explain that the act of the mind, which we call belief, and give an account of the principles from which it is derived, independent of the influence of custom on the imagination, and let its hypothesis be equally applicable to beasts as to the human species; and after he has done this, I promise to embrace his opinion. (THN, 178) 
Hume's philosopher hopes to operate with only one notion of belief, and rebuild mental life out of it. Of course actually Hume does not follow his own strictures, and he ends up giving a fairly complex account of mental life. But is official slogan is just the opposite. The syndrome is pervasive in current philosophy of mind. It is present, for instance, in Fred Dretske's informational conception of the mind, which hopes to reconstruct intentionality from simple to more complex organisms.

I shall not be able here to defend a layered conception of mind in general. I shall only concentrate upon a layered conception of one mental attitude, albeit a central one, belief. My objective is to suggest that there cannot be any simple and austere conception of belief, applicable both to animals and to men, and which could account for all the kinds of mental attitudes which fall under the name of "belief". So I shall try to propose a conception of belief which will allow a number of layers or levels of beliefs. Of course a multilevel conception is inspired by the hierarchy of levels of explanation which has been so prevalent in cognitive psychology. But surprisingly, a number of philosophers who defend cognitive science and the computational theory of mind have tended to have a fine grained and modular conception of sensory modalities, and of perception, although they had an undifferentiated conception of belief.

Belief, for Fodor, belongs to the "central system" of cognition, of which we do not know very much. The layered conception of mind is not opposed to stressing the continuity of mental states from animals to humans. On the contrary, it agrees with the idea of a continuity of levels in nature, which is present both in the emergent tradition and in the contemporary views inspired by the metaphysics of supervenience (Kim, 1999). I am not concerned here with this grandiose picture, but I want to suggest, from an examination of the different taxonomies of believing in contemporary philosophy of mind and psychology, that we could not understand the continuity if we operated with a simple, not a complex, taxonomy. Of course there is always a risk, in making too many distinctions, the risk of scholasticism. But if the distinctions are justified, it is worth running the risk. 


\section{The hierarchy of intentions}

In order to indicate better what I mean by a layered conception of mental states it will be useful to take a first example, the case of the notion of intention. According to what is called the causal theory of action, an agent does action A if and only if there is a psychological cause of $A$ which explains why the agent $\operatorname{did} A$. Traditionally the mental antecedents which are the causes of actions are intentions, conceived as a species of inner event. But according to Davidson (1980), who follows in this Anscombe (1958), intentions are not sui generis or categorical, but syncategorematic or derived mental states, which can be expressed as combinations of other mental states, in particular beliefs and desires. Thus my intention to go to the movies is just my desire to go to the movies and my belief that the theatre is open. But there is not, in between my desire and my belief on the one hand, and my action of going to the movies, any intermediary mental state of intention. The causal theory is typically an austere conception of intention, since it just gets rid of them.

But this simple version of the theory encounters several difficulties. I shall not review them here. The most famous is the deviant causal chains problem, emphasised by Davidson. A man may have the intention to kneel down in front of his beloved in order to declare his passion to her, but he may be so nervous and trembling at the relevant moment that he accidentally falls down on his knees. In this case he had the intention, hence the appropriate belief and desire, and he ended up doing the very thing that he had intended to do, but obviously the action was not caused by this intention. In order to deal with this problem, and without rejecting the causal theory, a number of philosophers have proposed more fine grained conceptions of intentions as the causal antecedent of actions. Davidson (1980) himself distinguishes in practical reasoning a conditional judgement to the effect that a certain kind of action is desirable all things considered, and an "all out" judgement contemporary to the action itself. Searle (1983) distinguishes two levels of intention: prior intentions, which are approximately complexes of beliefs and desires, and "intentions in action", which are the proximate causes of the physiological chain leading to behaviour. In our example, the man falling on his 
knees has a prior intention to fall, but no intention in action.

Searle's twofold conception of intention implies, contrary to the simple causal theory, that intentions, both prior and in action, are categorical mental events, which cannot be reduced in terms of complexes of beliefs and desires. But it still leaves unclear the exact content of intentions in action and of prior intentions. It has been developed in both directions. Bratman (1987) has shown that prior intentions could be conceived as elements of plans, which have a hierarchical and dynamical structure, and which constitute the framework of deliberation for an agent. Planning intentions involve a commitment of an agent in favour of his future actions. Plans can be revised and redirected, depending upon constraints that agents encounter in the course of their deliberation. The content of intentions in action needs also to be made more precise.

Recent work on the neurophysiology of action, in particular by Jeannerod (1997), has provided evidence that basic actions such as moving one's arm or trying to hit a target are closely associated to internal motor representations not only of their goal but also of the configuration of the body. These motor representations, which are largely based on imagery, are processed at a largely unconscious level, and prepare the movement. They are also activated when a subject observes someone else performing the action (this is connected to the famous mirror neurons). Drawing on Jeannerod's work, Elisabeth Pacherie (2000) has proposed a threefold distinction between three levels of intention:

a) Motor intentions, as just described

b) present intentions which start up the action, guide it, and sustain it

c) future intentions, which anticipate the action in deliberation

The last two only are conscious, although motor intentions can be partially conscious and involve the experience of acting. This feature of the model shows that a multilevel conception of intention must make room for attributions of intentions to agents at a sub personal level. Another feature of this three-level model is that intentions range from the more coarse grained (future intentions and plans) to the more fine-grained (motor intentions).

The hierarchical model of intentions is not the only example of multilevel conception of mental states. Theories of vision, such as Marr's (1982) and Ullman 
(1996) distinguish different levels of visual processing, with different kinds of representations involved. Theories of perception show the need to postulate several levels of perceptual content. Typically such theories make the distinction between what Evans (1982) called informational or non conceptual content on the one hand and conceptual content on the other hand. For instance Peacocke (1992) makes a distinction, within perceptual content, which he takes to be nonconceptual, between "proto-propositional" and "scenario" contents. Theories of consciousness also increasingly employ distinctions between kinds of consciousness (Block, 1995).

\section{The conundrums of belief}

It is a commonplace that our ordinary folk psychological concept of belief is something of a mess. It is subject to a variety of tensions and dualities which make us suspect that it is hardly coherent.

1. We take belief to be a categorical state, indicating a yes-or-no attitude towards a proposition as true or false, but we also take it at times as a graded state, indicating a degree of confidence towards a hypothesis.

2. There are verbal or linguistic beliefs, expressible in words, which most human adults have, and non verbal beliefs that we ascribe to children and animals.

3. Some beliefs are said to be tacit or unconscious, whereas others are said to be explicit or conscious.

4. There are some beliefs that we seem to acquire spontaneously and through our senses (seeing is believing) or through testimony, whereas others are acquired through inference and reasoning

5. Some of our beliefs are just short lived or weak opinions which we are not prepared to defend, whereas others are deep commitments that we are prepared to defend against criticism and which we would not revise easily.

6. We must make a distinction between the informational states which underlie our beliefs, especially in perception, such as for instance the lower level processing of information in vision, from the kind of content that beliefs have. The former are presumably non propositional and non conceptual whereas the latter are 
propositional and conceptual. The former are sometimes called "subdoxastic" states (Stich, 1978), whereas the latter seem to belong to the genus of beliefs and doxastic states proper.

This is just a sample list of the possible dualities. They are not exhaustive. Now do these distinction belong to the general class of beliefs which would be the genus of which they are species, or do they mark out distinct sorts of mental states? And are these distinctions exclusive? For instance it might seem that the class of conscious beliefs and the class of linguistic beliefs overlap to a large extent, although there is the well known phenomenon of our tendency to believe what we are said, which Thomas Reid called our "primitive credulity". Similarly opinions seem to be a matter of degree, whereas commitments seem to be all-out or categorical. And so on.

One might try a prima facie taxonomy (Stevenson 2002).The following distinctions: linguistic/ non linguistic, primitive / inferential, subdoxastic / doxastic seem to be the most important. They allow the following taxonomies between kinds of beliefs

i) subdoxastic non verbal states ( ?)

ii) spontaneous non verbal beliefs

iii) inferred non verbal beliefs (?)

iv) inferred verbal beliefs

Categories (i), (ii), and (v) seem unproblematic. By definition subdoxastic states are not linguistically articulable. The question whether we can accept (ii) depends upon our willingness to ascribe beliefs to animal, although it seems quite natural to ascribe spontaneous non verbal beliefs to children. Are there any beliefs of kind (iv)? Can one reason non linguistically? Our taxonomy should also include another distinction, which I have not indicated yet. It is the distinction between beliefs proper, as attitudes to propositional contents, or fist-order beliefs, and beliefs about beliefs, or second-order beliefs (or higher order). The first kind of belief is directed at a certain content which represents a state of affairs. The second kind of belief is directed at a mental state and at its content. The distinction is very important in the psychology of development, since a number of works shows that the capacity of forming secondorder beliefs is a characteristic of human adults or children above 4 years old only, 
although the issue is moot. So we could try a more complex taxonomy:

(a) non verbal spontaneous first-order

(b) non verbal spontaneous second-order

(c) non verbal inferential first order

(d) verbal, spontaneous first-order

(e) verbal, second-order spontaneous

(f) verbal, first-order inferential

(g) verbal second-order inferential

I am not going to discuss here this taxonomy. I do not even pretend that it is good. But suppose that we need some sort of taxonomy of this kind. The question then is: should we take all the items in this list as beliefs? By what criterion? There are two strategies here, which illustrate our initial problem: either we decide to align our concept of belief upon the top on in this list (inferential verbal and second or higherorder), and we run the risk of chauvinism, by excluding much of the other states from the domain of belief, or we align our concept to the bottom of the list, and we run the risk of being too liberal. It seems more appropriate to start from a concept of belief which would lie at an intermediary level and which could capture most of these differences and resemblances between the concepts.

\section{The austere conception of belief}

We need some general notion of belief in order to see whether it could subsume the class of doxastic states. It can be formulated as the austere or minimalist conception of belief, which can be defined as the view according to which

A) A belief that $P$ is an agent's disposition to act in a way that would tend to satisfy, other things being equal, his desires in circumstances in which $P$ were true.

In other words, an agent who believes that $\mathrm{P}$ is one whose behaviour would maximise, other things being equal, the satisfaction of his desires. This is not meant as a reductive analysis, for beliefs, on this definition, are inter-defined with desires. Neither is it meant as a definition of individual beliefs, for it allows beliefs, so defined, to be related to other beliefs and desires, which might override the previous ones. Hence the restrictive clause: "others things being equal". So the 
definition is not meant to be behaviouristic. It allows that different sets of beliefs and desires might be compatible with different behaviours. Hence belief, on this definition, is underdetermined by behaviour.

Definition (A) has been spelled out quite well by Robert Stalnaker in what he calls the "pragmatic picture" of belief:

\begin{abstract}
Belief and desire are correlative dispositional states of a potentially rational agent. To desire that $P$ is to be disposed to act in ways that would tend to bring it about that $P$ in a world in which one's beliefs, whatever they are, were true. To believe that $P$ is to be disposed to act in ways that would tend to satisfy one's desires, whatever they are, in a world in which P (together with one's other beliefs) were true. (Stalnaker, 1984, 15)
\end{abstract}

Now this conception is compatible with the functionalist conception of belief according to which beliefs are identified by their causal roles, i.e. the role they play, together with desires and other mental states, to produce behaviour. It is in fact quite a liberal conception. It does not specify to what kind of entity the propositional attitude of belief is related - a linguistic entity such as a sentence? An abstract entity like a proposition or a set of possible worlds?

The minimalist conception of belief (A) can be expanded to include more features of our ordinary concept of belief. The following, I think, captures the main features:

(A1) Beliefs are normally shaped by evidence for what is believed and concern for the truth of what is believed (they "aim at truth")

(A2) Beliefs are not subject to voluntary control; one cannot normally believe at will

(A3) Beliefs are subject to an ideal of integration; other things being equal, one should be able to agglomerate one's beliefs into a larger, coherent, view

(A4) Beliefs are not contextual, in the sense that, at a given time, an agent believes that $\mathrm{P}$ or not; he does not believe that $\mathrm{P}$ relative to one context but not relative to another. (Of course one can believe that $\mathrm{P}$ in one context and then that not $\mathrm{P}$ in another; but it is a case of changing one's mind, not a case of having the same belief in two distinct contexts).

A very important feature of this minimalist conception is that it is supposed to 
apply to a rational agent. In other words, it is supposed to be normative. It does not say that there cannot be any irrational beliefs, which would violate the principles (A1) - (A5) or one of them, but that the farther a given mental state diverges from this standard, the less it is recognizable as a belief.

This can be seen from a comparison between this minimalist concept of belief and a concept which is often invoked in some discussions in psychology and in artificial intelligence, that of tacit or implicit belief (Lycan, 1985). A number of discussions of procedural vs. semantic memory, but also of phenomena like blind sight, seem to justify the idea that some of our beliefs may be tacit, in the sense of not directly present to the mind, although they are supposed to be causally active in the behaviour and other responses of agents. But the extent of such tacit believing is unclear. They are pieces of inexplicit information which can vary in extent. Two kinds of examples are generally given. There are cases of absentmindedness such as the following. I gave my watch to the jeweller for repair; but just out of the shop, I routinely look at my wrist for checking what time it is. If asked, I would have said that my watch was now in the shop, but my behaviour belies this and can be taken as a manifestation of my tacitly believing that my watch is still on my wrist. Somewhere, in spite of my consciously believing the contrary, the information is stored that I still have my watch.

There are also more problematic cases of inexplicit information which can be deduced from my previous beliefs. Some are trivial: if I believe that Ankara is east of Istanbul, then I tacitly believe that Istanbul is west of Ankara. So are less trivial: I tacitly believe that elephants do not wear pyjamas in the wild, but this thought does not cross my mind quite often. What is wrong with calling such states beliefs? What is wrong is that they may be informational states based on contents stored in memory, but they do not guide action in the way normal belief do. Except perhaps in a quiz show, I would not normally have any use of the "belief" that elephants do not wear pyjamas. This is why such tacit beliefs are no more beliefs than plastic flowers are flowers. This is also the reason why subdoxastic states are not beliefs. But the case is different for those tacit beliefs which we can ascribe on the basis of 
behaviour. 6 This is the same, as we shall see, with partial beliefs.

There is an even more austere conception than (A). For $(A)$ assumes that belief is a relation to an entity which is susceptible of being true or false, proposition or sentence. It presupposes, to use a famous expression, that beliefs "aim at truth", or are directed to the truth. But in so far as belief is here defined as an attitude leading to action, it can be argued that this feature is unnecessary. Belief can simply be taken to be the subjective probability that an agent assigns to a state of affairs, given his desires and values. The Bayesian redefines (A)-beliefs as subjective probability functions or degrees of confidence.

B) The belief that $P$ is the degree of confidence (subjective probability) that an agent has in $\mathrm{P}$, measured by the odds upon which he is prepared to bet upon the truth of $P$, given his degrees of desires and values.

This is often called the betting quotient conception of belief: a person's degree of belief or his subjective probability is determined by his preference concerning gambles.

An agent has a subjective probability function $P$ just in case there is a utility function $U$ such that his preference maximise expected utility relative to $P$ and $U$. This is of course the conception of belief which was first formulated by Ramsey (1926), and taken up with the whole Bayesian tradition in the XXth century.

(B) satisfies the same conditions as (A). It satisfies also Hume's constraint in being applicable to animals as well. Indeed Richard Jeffrey (1986) has shown that it could be applied to rats.

A laboratory rat that sees nothing to choose between two food pellets must press lever $A$ or lever $B$ in order to prevent pellet $A$ or pellet $B$ from dropping out of reach while the bell is sounding. It sees pellet $A$ as less likely than $B$ to remain accessible after lever pressure prevents immediate disappearance, having seen pellets in each place disappear randomly, throughout its conditioning, with disappearance rates $A$ and $B$ set at $3 / 2$.

\footnotetext{
${ }^{6}$ See the discussion in Maloney 1992 and Crimmins 1992, who propose the following definition of (real) tacit belief: $A$ at least tacitly believes $P$ just in case it is as if $A$ had an explicit belief in $P$.
} 


$$
\mid \begin{aligned}
& p, q \\
& T(=p \vee \varnothing p) \\
& \varnothing q \\
& \varnothing p
\end{aligned}
$$

the odds on $p$ are the ratio $u(T)-u(\varnothing p): u(p)-u(T)$ of the marginal utilities of $p^{\prime} s$ falsity and truth. Here odds on $p$ are $3: 1$, on $q, 1: 1$

Where $p$ and $q$ are the propositions that the rat eats pellet $A$ and eats pellet $B$, the rat is indifferent between $p$ and $q$, but prefers $\varnothing q$ to $\varnothing p$, i.e. prefers losing access to the pellet he thinks less likely to go away. This pattern of preference indicates that the rat judges $p$ to be more probable than $q$, even though he has no explicit concept of subjective probability. (Jeffrey, 1986)

Now it is perfectly possible to adapt the main features (A1) - (4) of the (A) conception of belief to the (B) conception:

(A1) Beliefs are normally shaped by evidence for what is believed and concern for the degree of confidence of what is believed

(A2) Beliefs are not subject to voluntary control; one cannot normally believe at will

(A3) Beliefs are subject to an ideal of integration; other things being equal, one should be able to agglomerate one's beliefs into a larger, coherent, view

(A4) Beliefs are not contextual, in the sense that, at a given time, an agent has a given degree of confidence or another; he does not have a degree of confidence in $\mathrm{P}$ relative to one context but not relative to another

Now the Bayesian insists strongly on the rationality constraint of these definitions. The fact that these criteria of rationality can be extended to rats shows that they are very minimal indeed.

But there is a problem. Are the (A) and the (B) conceptions really compatible? Suppose we accept the austere conception of belief (B). Then it seems that we do not even need to admit such states as beliefs in the categorical or qualitative sense 
as relations to sentences or propositions. As Patrick Maher (1986) puts it:

Bayesian decision theory does not make the rationality of a person's actions depend in any way on his beliefs. According to Bayesian decision theory, the rationality of a person's actions depends not on his beliefs, but rather on the degrees of confidence that he has on various propositions. So for example, a person would be rational to accept a bet on the proposition $A$ at odds of 9:1 just in case he is at least $90 \%$ confident that $A$ is true. Whether or not the person believes that $A$ is true is quite irrelevant; all that matters to the rationality of the decision is the degree of confidence the person has in $A$. (Maher, 1986, 377)

It might be thought that there is a simple relationship between categorical or full belief and the degree of belief or partial belief, such that we could alternatively talk in terms of $(A)$ or of $(B)$. But it is not the case. Neither can we reduce one to the other.

\section{Partial vs. full beliefs}

Can the Bayesians simply claim that full beliefs have to be replaced by partial ones? This is the line taken by radical probabilists such as Jeffrey (1992). The concept of full belief would then be idle or epiphenomenal. The trouble is that it is difficult to dispense with the concept of full belief. On the Bayesian picture one can have a very high degree of confidence - say between 0.8 and 0.9 - in a hypothesis, but they question can still arise whether one really believes it. The conduct of inquiry, however, especially in scientific matters which Bayesians hope to illuminate, does seem to call for categorical, beliefs, not for partial ones.

The literature about the descriptive inadequacy of Bayesian approach in everyday life and in actual description of scientific practice is replete with examples. Beliefs, the critics argue, are like love, patience, jealousy, aesthetic pleasure, hope, understanding, etc. They too come in varying degrees, but their strength cannot be measured with equal precision. It is undeniable that some loves, some jealousies and some aesthetic pleasures are stronger than others, but it would be a mistake to suppose that they can be amenable to precise numerical scales. To that Bayesians reply that the conscious feelings of conviction which one associates with a belief are distinct from their real strength. As Ramsey says: "The beliefs we hold most strongly are often accompanied by practically no feeling at all; 
no one feels strongly about the things he takes for granted" (1926). But the problem is that no piece of behaviour and no expression of betting preference are indicative of a specific degree of belief with a specific content.

The point is not simply that it is extremely difficult to measure the degree of a belief according to the Bayesian standards. The point is rather: if the Bayesian admits that there are full beliefs in addition to partial beliefs, how will he account for the former?

There are three sorts of views that he can take.

Many Bayesians endorse the view that full belief is a state of high confidence. This simply reduces categorical belief to high degree of belief. But what degree is? Suppose it were certainty:

Certainty view. You count as believing P only of you assign a value 1 to your degree of belief in $P$.

The problem with this view is that if it were correct, the a person ought to be prepared to accept any bet on the truth of her beliefs; for by (B) a rational person is supposed to act in the way that would be best if her beliefs were true, and if her beliefs are true, then he will win any bet on those beliefs. But this means that a rational person will bet on his beliefs at any odds. This also means that person must be prepared to bet, at any odds, for each proposition which is incompatible with her beliefs, that it is false. This sounds crazy.

The second, and most common, view would be that full belief is a high level of confidence.

Confidence threshold. There is a threshold $r(<1)$ such that a rational person believes that $\mathrm{P}$ only if her degree of confidence in $\mathrm{P}$ is greater (or not less than) $r$. The problem is that if one hold this confidence view, is that a high degree of confidence is neither sufficient nor necessary for full belief.

That it is not sufficient is shown by the lottery paradox:

The lottery paradox. Consider a fair lottery of $n$ tickets. A person's confidence that a given ticket will not win should approach certainty as the number of tickets is increased. So if $n$ is sufficiently large a rational person will have a degree of 
confidence greater than the threshold level $r$ that any given ticket will win. He will also be fully confident (at degree 1 ) that at least one ticket will win. A rational person, then, will believe each of the propositions:

Ticket 1 will not win

Ticket 2 will not win

Ticket $n$ will not win

One of the tickets 1 to $n$ will win

But these propositions taken conjunctively are inconsistent. Hence if belief is high confidence, a rational person will have inconsistent beliefs. In spite of its high probability, the person should not believe the conjunction. Hence high confidence is not sufficient for belief.

In order to restore consistency, the partisan of the high confidence view must deny that the set of propositions can form a conjunction. Given that the conjunction of $A \& B \& C \ldots \& N$ is a deductive consequence of the individual propositions $A, B, C$...N separately, it would follow that a person must not believe the logical consequences of her beliefs.

A parallel argument shows that the high confidence view is not even necessary for belief, through the Preface paradox.

The preface paradox. You write a book, a work of nonfiction. You have a high degree of confidence in each of the propositions in the book, otherwise you wouldn't write it. But in the preface you admit, as any honest writer, that your book may contain mistakes. So it is rational for you to believe that at least one of the claims in the book is false. But this contradicts your previous assertion that the conjunction of your assertions in the book is true. In this case, you should believe that conjunction, despite its low probability. Hence high confidence is not necessary for belief.

The preface and the lottery paradoxes show that the problem with the view that belief could be identified with partial belief has nothing to do with the vagueness of the notion of degree or with the difficulties of measuring partial 
beliefs. The problem is that there is not seem to be any threshold, not even a vague one.

The Bayesians have proposed another conception of full belief, according to which beliefs are just behavioural dispositions to act. This is indeed a version of (A): The act view You count as believing $\mathrm{P}$ just if, when confronted with a decision problem so described that it is obvious that doing $A$ will, in the event that $P$, have the outcome that you prefer, your are disposed to choose $A$.

The problem with this view is that unless you are certain that $P$ is true (which would come back to the certainty view), a rational agent will act as if $\mathrm{P}$ were true in some circumstances, and as if $\mathrm{P}$ were false in other circumstances. But suppose you can be in two scenarios, which involve the choice respectively between:

a) status quo and betting $1 €$ on $P$ for a return of $10 €$

b) status quo and betting $10 €$ on $P$ for a return of $1 €$

Now suppose your confidence in $P$ is only 0.5 . Then you would be disposed to take the bet in scenario (a), acting as if $P$ were true, but reject it in scenario (b), acting as if not $P$ were true. But remember that we have said that the austere conception of belief reject the context sensitivity of belief. Or we should say (more on this below) that the agent here accepts a proposition in one context, but not in another.

Other writers (Kaplan 1996) have proposed the view that full belief should not be identified to a sort of act of betting on the part of the agent, but on the act of asserting a proposition with the only aim of saying what is true.

The assertion view. You count as believing $\mathrm{P}$ just if, if your sole aim were the truth, and your only option to assert $P$, assert that not $P$, or suspend belief, you would prefer to assert $P$.

On this view there is no simple relationship between flat out belief and confidence. It implies that belief is a constant disposition to make assertions in certain specific circumstances, where one's concern is just the truth of a hypothesis. The view is that assenting to a belief, especially by asserting it, is taking the risk of putting it forward. It is compatible with this view that two individuals have the same confidence in a proposition - the same partial beliefs - but a different full belief. 
What is the upshot if this? It is not that full belief must replace partial belief, as if we were following Descartes in his second Rule for the direction of the mind, where he enjoins us not to give credence to any proposition which would be simply probable.

The conclusion is rather that there are two distinct, species of belief, the partial kind and the flat or categorical one, and that neither can be reduced to the other.

There are good reasons to consider that this correspond to psychological realities. The lottery and the preface paradox show that it can't be rational to hold both that we have full and partial beliefs. But we are fallible agents, and we can often found ourselves in such situations. For instance we step in a Turkish Airline aircraft, we have good confidence that it will not crash, and we have also high confidence, about each Turkish Airlines flight in the coming year, that it will no crash. But we have heard about the crash of some Turkish Airlines planes. And so we have good reason to believe that there is at least a small likelihood that one of them will crash. Several writers have suggested that there could be two distinct but coexisting systems in our mind, one Bayesian sensitive to degrees of belief, the other not (Osherson, 1981).

\section{Belief and acceptance}

The lottery paradox illustrates the fact that the concept of belief is often associated with normative commitments: someone who believes that $A$, that $B$, that $C$ ought to believe that $A \& B \& C$ which deductively follows. When someone is attributed the belief that $P$, there are certain things that he ought to believe in virtue of the fact that he believes that $P$. When someone believes that $P$, and in addition believes that if $P$, then $Q$, then he ought to believe that $Q$. This seems just a consequence of the feature of rational integration (A4) which I mentioned above.

But the lottery paradox as well as the preface paradox illustrates the fact that someone can fail to live up to his commitments. After all, agents can fail to be rational. Someone who is self-deceived can believe that $P$, and as a result of his desire that not $\mathrm{P}$, come to believe that $\mathrm{P}$. This is irrational, but it is common. Would be say that he does not believe both that $\mathrm{P}$ and that not $\mathrm{P}$ ? Similarly someone who 
would fail to infer $Q$ from $P$ and if $P$ then $Q$ would not believe what he ought to, but if he believes $\mathrm{R}$ instead, there is no reason to deny that believes $\mathrm{R}$. There are cases where we find ourselves believing that $P$, but where we also think that we ought not to believe it.

We must make room for a distinction between the beliefs that a subject intends to commit himself to, and those which he just finds himself having, as a matter of instantiating a certain causal disposition. For instance I may believe that this dog is dangerous, and act accordingly, without intending to commit myself to the claim that this dog is dangerous. On the other hand I may want to commit myself to the truth of a certain scientific hypothesis without being sure I shall act upon it in all circumstances external to the laboratory. The distinction here is between what Kant called "pragmatic belief" and belief proper in the Canon of Pure Reason, and belief proper, and which he illustrated with the example of a physician who does not believe fully that. In contemporary terminology, it is often formulated as the distinction between belief and acceptance (Stalnaker, 1984; Cohen, 1992). In some terminologies, "acceptance" designates simply what I called above "full" or "flat out" belief. But this is not the sense intended here.

Jonathan Cohen defines acceptance thus:

"To accept that $p$ is to have, or to adopt a policy of deeming, positing, or postulating that $p-$ i.e. of including that proposition or rule among one's premises for deciding what to do or think in a particular context, whether or not one feels it true that $p . "$ (Cohen, 1992, 4)

Acceptances in this sense share a number of features with full beliefs - they are conscious, often linguistically expressed - but which differ in a number of respects. We can in this sense contrast (A1)-(A4) with

(A1') Acceptance is voluntary or intentional, unlike belief. In a certain sense, it is a form of decision to believe.

(2') Acceptance can aims not at truth, but at utility or success. In this sense it is a pragmatic notion, not a cognitive or theoretical one. One can accept certain things that one believes to be false.

(3') Acceptance, for the same reason, need not be shaped by evidence or evidential reasons.

(4') Acceptance is not regulated by an ideal of rational integration in the 
same sense as belief. I may, for pragmatic or perhaps social reasons, accept certain things which do not cohere with my other beliefs.

(5') Unlike belief, acceptance is context-dependent.

(6') Acceptances are not a matter of degree

There is no doubt that there are states of acceptance in this sense. There are things that we take for granted and feel committed to in certain contexts, but not in others, propositions that we consider for the sake of a reasoning without being prepared to endorse them in other circumstances, etc. Acceptances occur most of the time in the course of a deliberation about what propositions to hold. They differ in this sense strongly from partial beliefs as states of confidence. For this reason, it may be doubted that they can belong to the category of belief proper, especially because they are intentional, contextual, and can be shaped by concerns independent from the truth of the proposition believed. Some cases of acceptance, in this pragmatic sense, are more cases of feigned or simulated belief (behaving as if one believed), rather than beliefs proper.

Certainly we must be able to make a difference between insincere or faked expressions of belief on the one hand, those that we assert tongue in cheek, and true and sincere commitment to a credo on the other hand. If this distinction could not be made, books like Lucien Fèvre's Le problème de l'incroyance au XVlème siècle would be impossible to write. Nevertheless, there are acceptances with, although contextual, are aimed at truth. These are the hypotheses that we make in the course of inquiry without believing them fully, or the propositions that we consider for the sake of a reductio ad absurdum within a proof. These are the proposition that we take to be true at a certain time, but do not necessarily hold true. We can call them alethic acceptances, and reserve the term pragmatic acceptances for those with are not truth-oriented. Some are short lived, and incur only as intermediate step in a deliberation, some are more lasting. Some of them may even belong to the general background of deliberation. For instance if I plan to construct a house, I have better assume, or accept, that I have the money to do that. And there are more long term and structuring commitments.

The analogy between such acceptances and the plans which form the background of the hierarchy of intentions is obvious. Mutatis mutandis, 
acceptances are to beliefs what future intentions and plans are to present intentions. What is exactly their relation to dispositional beliefs and to partial beliefs? Some pragmatic acceptances of a proposition are compatible with a low degree of confidence in this proposition, even with disbelief in it. This is Kant's example of the physician would have a low degree of confidence in the hypothesis that his patient has tuberculosis, but who nevertheless accepts that it is the case: better err on the side of prudence. But apart from cases of fiction or play, it is very unlikely that acceptances are not based on any partial belief about the truth of a proposition. The attitudes are distinct, but there are most of the times based on the same states. Indeed acceptance is most of the time based on belief. (See Bratman (1999) the example of the man who builds a house).

\section{The hierarchy of beliefs}

If the preceding is correct, we can construct a hierarchy of levels of beliefs, or at least of doxastic attitudes, comparable to the one that we have envisaged for intentions (see Stevenson 2002, Frankish 2004 for other such attempts).

\begin{tabular}{|c|c|c|}
\hline & $\begin{array}{l}\text { subdoxastic states } \\
\text { modular proto-beliefs }\end{array}$ & $\begin{array}{l}\text { non conscious } \\
\text { passively formed } \\
\text { non linguistic } \\
\text { probability logic } \\
\text { shared by animals }\end{array}$ \\
\hline $\begin{array}{l}\text { FIRST LEVEL } \\
\text { BELIEF }\end{array}$ & $\begin{array}{l}\text { tacit beliefs } \\
\text { partial beliefs }\end{array}$ & \\
\hline $\begin{array}{l}\text { SECOND LEVEL } \\
\text { BELIEF }\end{array}$ & $\begin{array}{l}\text { full / categorical beliefs } \\
\text { alethic acceptances } \\
\text { pragmatic acceptances }\end{array}$ & $\begin{array}{l}\text { conscious } \\
\text { can be actively formed } \\
\text { often linguistic } \\
\text { human }\end{array}$ \\
\hline
\end{tabular}

I have indicated a line between the group formed by tacit belief and partial beliefs on the one hand, to indicate the division between two strands of belief. If this taxonomy is correct, and if the parallel with intentions can be made, one could 
make similar distinctions for other kinds of mental states, and have a division into desires as desirabilities on the one hand, and conscious goals on the other. The distinction between non conscious/conscious, passive/active, and linguistic/non linguistic marks important differences. It is not to make a very bold hypothesis to suppose that these divisions mark important architectural boundaries of subsystems in the mind, and that they have distinct evolutionary bases in the brain. But it is not the place here to discuss this point.

It should also be clear from this schema that although these different kinds of mental states figure at levels which are autonomous, they nevertheless are continuous, in the sense that they depend on each other. But in what sense? In what sense is full belief a higher order kind of belief and acceptance a level higher? We can ask this question in another way, but asking how these levels could be compatible with each other. If we accept, with the Bayesians, that a first level of beliefs is rule by the logic of partial belief (the rules of coherence are those of probability), and that full belief and acceptances are rules by deductive logic, how can they coexist, for they deliver distinct verdicts, as the lottery paradox shows? In other words, how is it possible to enrich the concept of belief by moving to higher levels if the austere minimalist Bayesian conception forms the basis of our doxastic mind? We come back to the previous dilemma: if our actions and deliberations are guided by our partial beliefs and desires, how is can full beliefs and acceptances be other than idle a purely epiphenomenal? And if they are not, do not we have a case of over determination, an agent obeying both to his Bayesian mind and to his classical mind?

How is it possible, in other terms, to accept both (i) the a great number of our beliefs are less than certain and (ii) that it is possible, if not desirable to conform to the requirement of deductive closure of our beliefs ? My answer is here inspired by that of de Sousa (1971) and Kaplan (1996) already hinted at above under the name of the assertion view. We have partial beliefs and desires, which are behavioural dispositions, and which are subjective utilities and probabilities, obeying the Bayesian laws of the dynamics of beliefs (mainly conditionalisation). But, on the basis of these, we make "bets on truth alone". The kind of relation that we need here between level 1 and level 2 beliefs and acceptances is that of supervenience: 
our level 2 beliefs are realised in our level 1 beliefs, and they co-vary with them, in the sense that there cannot be any difference in our level 2 beliefs without a difference in our level 1 beliefs. But supervenience (in this sense) does not entail reduction. 7

Two other important themes follows from this scheme of classification. The first has to do with the role of rationality. I have already noted that the austere conception of belief is associated with a very general notion of rationality: a notion of belief satisfying conditions (A1)-(A4) is supposed to be rational. Similarly for (B1)-(B4) where the concept of rationality is that of the Bayesian logic of coherence (you count as rational in your beliefs if they obey the laws of probability and the principles of preference). But, if the preceding is correct, the concept of rationality does not apply to belief across the board. First, as we have seen, there are conflicts between the criteria of rationality as they apply to partial belief and as they apply to full belief. If, in addition, we accept that there can exist proto-beliefs, or tacit beliefs, especially in animals, there is no reason to suppose that the same kind of principles of rationality apply at these levels. If this is correct (although I cannot examine this point), we should expect that the concept of rationality too should be a layered one, with different levels.

This of course raises the second point, which has to do with the relationship of thought to language. The austere conception of belief, as I have remarked, can be applied to animals. But there is a familiar opposite move: take the austere notion of belief and restrict it to creatures capable of language only. Beliefs then become essentially relationships to sentences. And this leads to the opposite view that animals do not (and could not have beliefs (Davidson 1980). Here austerity leads to chauvinism. If we accept the layered conception of belief, there is no difficulty in claiming that both animals and humans have beliefs, although not the same kinds of beliefs. I cannot, however, deal here with all the consequences of this view. (See Bermudez, 2003)

Finally let me illustrate briefly some consequences of the layered conception of belief for psychological research. If the (basically) two-level conception is

\footnotetext{
${ }^{7}$ The image of the continuity of levels is reminiscent of the metaphysics of emergence (see A. FagotLargeault, 2002). But my perspective here is closer to that of supervenience physicalism.
} 
correct, we should expect to find dualities of belief and dissociations between levels in a number of domains. And this is indeed the case. I have already mentioned the homely case of self deception. The standard description of self deception is that an agent believe that not $P$, but out of his desire to believe that $P$ manages to believe that $P$, so he in a contradictory state, that of believing that $P$ and of believing that not P. On the view proposed here, it would be more appropriate to say that he believes that not $\mathrm{P}$ but accepts that $\mathrm{P}$. This does not diminish his irrationality, but it brings a new light to the kind of dissociation which can be observed here.

Let me mention two other applications. In psychopathology monothematic delusions have been widely studied, especially those like the Capgras illusion (where subjects are under the illusion that a member of their family has been replaced by an impostor. A common explanation of this delusion is that these subjects suffer a special of brain lesion or impairment, which makes them recognise a familiar face as unfamiliar (Ellis and Young 1990), and then trying to make sense of the disturbing experience by rationalising it. If this kind of explanation is correct, we have here a clear dissociation between the belief system and the acceptance system. Finally, in the psychology of reasoning, a number of researchers have tried to explain the pervasive mistakes in ordinary deductive tasks such as the famous Wason task by invoking a dual level of mental processing: "heuristic" low level processes on the one hand, and "analytic" ones on the other. In fact there are quite a lot of examples of this kind, which militate in favour of a more fine grained and rich conception of representations.

\section{Conclusion: happy the rich in spirit}

I have not said anything very original, for the strategy of dividing, distinguish levels and hierarchies of representations is quite common in cognitive psychology. But it is often done from top to bottom. What I have suggested is that we extend it to the top layers, those which too many writings in this field continue to designate with the single term of belief. But it should also be clear that unlike a number of strategies involving levels in cognitive science, the present levels are not purely 
explicative: they intend to pick out real mental kinds, not artefacts of our explanatory strategy. The layered conception implies a realist conception of mind.

If this is correct, we should be very suspicions not only of austere conceptions of beliefs, but also, more generally, of austere conceptions of mind. The austere conception of mind was meant to be naturalistic. It hoped to show that a limited ontology of mental states could apply to the whole realm of nature by obeying the same principles. An austere physicalistic or behaviourist ontology imposed a division between the mental and the physical which is well illustrated by Quine's "double standard" of intentional idiom and of "austere idiom" of canonical notion, and by Davidson's anomalous monism. More surprisingly, perhaps, it is also illustrated by a conception of mind that has the pretension of being rich, namely the hermeneutic conception. From Dilthey to Ricoeur, the hermeneutic tradition emphasises the explicative gap between the domain of the mental phenomena and the domain of natural phenomena. It draws a sharp line between our mental life and that of animals. But if it adopted a layered conception of mind, the continuity should be obvious.

\section{REFERENCES}

Anscombe, E. Intention. Oxford, Blackwell, 1954.

Bermudez J. Thinking without language. Oxford, Oxford University Press, 2003.

Block, N. "On a confusion about the functions of consciousness". Behavioural and Brain Sciences. 1995.

Brandom, R. Making it explicit. Cambridge, Harvard University Press, 1994.

Bratman, M. Intentions, plans and practical reasons. Cambridge, Harvard University Press, 1987.

. Faces of intention. Cambridge University Press, 1999.

Cohen, L.J. An Essay on Belief and Acceptance. Oxford, Oxford University Press, 1992.

Crimmins, M. "Tacitness and virtual belief". Mind and Language. 7, 3 (1992): 241-261.

Davidson D. Essays on Actions and Events. Oxford, Oxford University Press, 1980.

Dennett , D. "How to Change your Mind". Brainstorms. Bradford Books, Mass, 1978.

Ellis, H.D. and Young, A.W. "Accounting for delusional misidentifications". British Journal of Psychiatry. 157 (1990): 239-246.

Engel, P. (ed). Believing and Accepting. Dordrecht, Kluwer, 2000.

."Peut-on parler de croyances délirantes?". In: J. Chemouni (ed). Clinique de I'intentionalit, In press, Paris, 2001.

Evans, G. The Varieties of Reference. Oxford, Oxford University Press, 1982.

Evans, J. S. B. "Heuristic and analytic processes in reasoning". British Journal of Psychology. 75 (1984). 
Fagot-Largeault, A. "L'émergence", in D. Andler, A. Fagot-Largeault, B. Saint Sernin. Philosophie des sciences, II. Paris, Gallimard, 2002. p.939-1048.

Fodor, J. The Modularity of Mind. MIT Press, Cambridge Mass, 1983.

Jeannerod, M. The cognitive neuropsychology of action. Oxford, Oxford University Press, 1997.

Jeffrey, R. "Dracula meets Wolfman, acceptance vs. Partial Belief". In M. Swain, Induction, acceptance, and rational belief. Dordrecht, Reidel, 1970. p.157-185.

. "Animal Interpretation". In: Le Pore, E. (ed). Actions and Events, Essays on the philosophy of Donald Davidson. Blackwell, Oxford, 1986.

1992.

Probability and the Art of Judgment. Cambridge, Cambridge University Press,

Kaplan, M. Decision theory as philosophy. Cambridge, Cambridge University Press, 1996.

Kim, J. Supervenience and mind. Cambridge, Cambridge University Press, 1999.

Krüger, L; Gigerenzer, G. et alii (eds). The probabilistic revolution. 2 vols. Cambridge Mass, MIT Press, 1987.

Levi, I. The enterprise of Knowledge. Cambridge Mass., MIT Press, 1983.

Lycan, W. "Tacit Belief". In Bodgdan, R. (ed). Belief. Oxford, Blackwell, 1999.

. "The Continuity of Levels in Nature". In Lycan, W. (ed). Mind and Cognition. $2^{\text {nd }}$ ed. Blackwell, Oxford, 1985.

Maher, P. "The irrelevance of belief to rational action". Erkenntnis. 24 (1986): 363-84.

Marr, D. Vision. San Francisco, Freeman, 1982.

Osherson, D. "Judgment" in Osherson, D. and Smith, E. An invitation to cognitive science, 3, 1981.

. Rationality. Cambridge Mass., MIT Press, 1981.

Pacherie, E. "The Content of Intentions". Mind and Language. 15, 4 (2000): 400-432.

Peacocke, C. A Study of Concepts. Cambridge Mass., MIT Press, 1992.

Pylyshyn, Z. Computation and cognition. Cambridge Mass., MIT Press, 1984.

Quine, W. v. O. Pursuit of truth. Harvard, Harvard University Press, 1990.

Ramsey, F.P. "Truth and Probability" (1926) in Philosophical Papers, ed. Mellor. Cambridge, Cambridge University Press, 1991.

Searle, J Intentionality. Cambridge, Cambridge University Press, 1983.

Sousa, R. de "How to Give a Piece of Your mind, or the logic of Belief and Assent". Review of Metaphysics. 25 (1971): 59-79.

Stalnaker, R. Inquiry. Cambridge Mass, MIT Press, 1984.

Stevenson, L. "Six Levels of mentality". Philosophical Explorations. 5, 2 (2002).

Stich, S. "Beliefs and Subdoxastic States". Philosophy of Science. 45 (1978): 65-76

Ullman, S. High level Vision. Cambridge Mass., MIT Press, 1996. 